\title{
Differences in Thinking Styles on the Perception of Business Analytics
}

\author{
Suslov S.A.* \\ Nizhny Novgorod State Economic and Engineering \\ University \\ Knyaginino, Russia \\ e-mail: nccmail4@mail.ru \\ Cheremuhin A.D. \\ Nizhny Novgorod State Economic and Engineering \\ University \\ Knyaginino, Russia \\ e-mail: ngieu.cheremuhin@yandex.ru
}

\author{
Igoshin A.N. \\ Nizhny Novgorod State Economic and Engineering \\ University \\ Knyaginino, Russia \\ e-mail: igoshin.nn@yandex.ru
}

\author{
Sibiryaev A.S \\ Financial University under the Government \\ of the Russian Federation \\ Moscow, Russia \\ gimu09@mail.ru
}

\author{
Bashashkina G.Y. \\ Military University of the Ministry of Defence of the Russian Federation \\ Moscow, Russia \\ bashashkina@mail.ru
}

\begin{abstract}
The research subject is business analytics or business intelligence (BI). The purpose of the research was to study the influence of the respondents' thinking styles on their perception of the impact of business analytics on other characteristics of the organization. On the basis of the questions developed by the authors in combination with the Russianlanguage adapted version of the questionnaire of thinking styles, the correlation of these factors was estimated, which allowed proving the assumption of this relationship. In particular, it was found that if a person is exposed to synthetic or pragmatic style of thinking, he higher he evaluates the degree of influence of business intelligence on the innovativeness of the organization, and if the person subject to the pragmatic style of thinking, it is lower than estimates the degree of influence of business intelligence on the dynamics of the organization. This analysis was carried out on 4 characteristics of the organization. The fact of the relationship established in the study opens up a significant problem field and is the main one for future research.
\end{abstract}

Keywords - business analytics, efficiency, innovation, thinking style, organization innovativeness, organization dynamics.

\section{INTRODUCTION}

The conditions of modern business have changed significantly since the last year decade. Nowadays the period of commercial business existing became shorter, the competitiveness became higher, technologies changed quickly [1-4], the era of digital transformation fundamentally changed the existing cost chains [5], that caused the readiness of decision making means competitive advantage. The effectiveness of management decision-making today depends on the availability of timely and accurate business information, the availability of a large amount of incoming data, information and knowledge. [6]. In addition, researchers today distinguish unique knowledge as a separate source of values, the use of which can result in obtaining competitive advantages [7].

For making right decisions companies need intellectual instruments with business analytics instruments for data analysis. Instruments and concepts of information systems began, related to informational systems, begin to take priority when making strategic plans and decisions. Today, firms invest in data to extract valuable information and use it for operational, tactical, and strategic purposes. [8]. Nowadays quality and timeliness of business analytics of organization mean not only difference between profit and loss but also difference between existence and bankruptcy.

In modern society the term «business intelligence» (BI) в appeared in 90-s and was used for description of to describe activities and tools related to reporting and data analysis [9] However, now different authors have different explanation of business analytics issues. It can be often defined as process of transformation raw data into useful information to support the implementation of effective business strategies; collecting business data and getting the necessary information that certain users need, at the right time, through the right channel. The work [9] is based on the interpretation of BI as a set of strategies, processes, applications, data, products, technologies, and technical architecture used to support the collection, analysis, presentation, and dissemination of business information [9]. In the study [6], it is indicated that the term BI can be used to refer to: 1. Relevant information and knowledge describing the external business environment and its position in relation to its markets, customers, competitors, and economic problems; 2. An organized and systematic process by which organizations can obtain, analyze, and distribute information from internal and external 
sources of information that are relevant to their business activities and decision-making.

Some researchers suggested that this term is very wide and complicated which has not united definition. [10].

This concept is also interpreted differently in management and management Sciences. Some authors use the term BI to refer to the concept of "environmental intelligence", which describes how managers study the external environment in relation to their organization; others refer to competitive intelligence or analysis; some focus on technological intelligence focused on technological dynamics. The classical interpretation of business Analytics in this context is presented in [11]: "we understand BI as a set of technologies, methods, systems, processes, and applications used to collect, store, analyze, and transform business and market data and information into relevant knowledge for use in making management decisions."

Over the past few years, two fundamental papers have been published $[12,13]$ on bibliographic and thematic analysis of research in the field of business Analytics, based on the study of which the following conclusions can be drawn:

- in the period 2014-2017, the most frequently used keywords in business Analytics publications were: "management", "knowledge management", "social media", "text mining", "cloud computing", "data ware house", "data mining", "data science", "big data analytics", "information system", which is consistent with the previously identified division into technological and managerial understanding of the essence of business Analytics;

- the number of publications on this topic has been growing since 2007 and reached a maximum in 2016-2017 (14 publications);

- the main practical problems associated with the implementation and application of business Analytics are: lack of motivation of the organization's staff, fear of losing control over information processes and flows (the introduction of business Analytics entails changing requirements for professional skills, approaches to making management decisions), lack of necessary knowledge and technical skills, the presence of system infrastructure problems, insufficient coordination between it staff and information users;

- two subdirectories are identified as promising areas of research: focusing on organizational and infrastructure aspects of using and implementing business intelligence systems, and research in the field of evaluating the performance and other performance parameters of these systems.

In addition, applying business intelligence is a multifaceted process. Although the use of these systems has the potential to bring great benefits, it requires significant specific resources, and some of the benefits may be indirect. As indicated in [14], the introduction of business intelligence systems requires significant investment in technology and personnel, which significantly reduces the possibility of using this system in small business organizations. In large organizations, however, due to their size, it is necessary to take into account the lagging influence of various innovative activities on the company's performance [16]. In addition, a rapid change in business needs should cause a rapid change in the structure of business intelligence [15] to ensure its continuous evolution

The problem of changing the structure of information flows and the functioning of the organization as a whole, caused by the introduction of business intelligence, is significant. As shown by numerous studies, the availability and degree of efficiency of this system affect:

- the degree of innovation in the organization;

- flexibility of the organization. [3]

- overall performance of the organization, including the start-up effectiveness of startups;

- quality and other characteristics of management decisions made; [17]

- a scheme for distributing information between employees and the possibility of " network training»;

- the "absorption capacity" of an organization, defined as the ability to use new external information for its own purposes. [16]

The analysis did not reveal the impact of the effectiveness of the organization and the industry in which it operates on the effectiveness of business intelligence implementation. This process largely depends on socio-psychological factors, such as the overall compatibility of staff with it technologies, their perception of changes in productivity caused by the use of business intelligence tools and common attitudes of employees. At the same time, studies have shown that a significant number of young entrepreneurs and business school students have vague and General knowledge about business Analytics and related processes.

\section{Methodology}

Based on this, the goal was to study the views of students and teachers of the Institute of Economics and management about business Analytics and its impact on the characteristics of the organization's work, as well as the influence of the respondents 'thinking styles on their views. To do this, we used a Russian-language adapted version of the InQ questionnaire developed by R. Bramson And Harrison [18], to which 4 questions were added, designed to find out the respondents' opinion about the nature of the impact of the business intelligence system on the characteristics of the organization:

1. An organization's innovation is defined as «the ability of a firm to introduce new ideas, experiment results, and use creative elements that can lead to new products, services, or processes." How big the relationship between an organization's innovation and different characteristics of business intelligence are? 
2. The term "dynamic" refers to "the simultaneous ability to recognize and respond to rapid changes, achieve the goals set for the organization, achieve different goals using the same methods, and perform the necessary actions in the shortest possible time". How big the relationship between the organization's dynamics and different characteristics of business intelligence are?

3. Today, innovative ambition is understood as "the ability to ' learn to learn', which helps to improve the perception and awareness of the current state of Affairs , use new opportunities and mitigate the possible consequences of dependence on one chosen path of development ". How big the relationship between an organization's innovative ambition and different characteristics of business intelligence are?

4. How big the relationship between the size of an organization (the number of resources it uses) and the different characteristics of business intelligence are?

The respondents were asked to give answers to these 4 questions using two dimensions:

1. What does it affect? Answer choice:

- the probability of making a decision to implement a business intelligence system in the organization,

- the effectiveness of the business intelligence system implementation in the organization,

- the effectiveness of the business intelligence system in the organization,

- to increase the effectiveness of the organization's activities as a result of the implementation of the business intelligence system

- on the perception of the results of the implementation of the business intelligence system);

2. How does it affect? Answer choice:

- influence is inversely proportional to;

- impact is directly proportional to;

- no effect.

The proposed method of measuring the influence of the preferred style of thinking on the opinion about the degree and nature of the influence of business Analytics on various parameters of the organization is as follows:
1. The answer to each of the 4 questions is encoded. The "impact is directly proportional to" response option is mapped to +1 , "no effect" to 0 , and "influence is inversely proportional to" to -1 .

After that, 2 values are calculated for each of the above questions: "the Importance of business intelligence" (considered as the sum of the absolute values of the codes) and "the Nature of the impact of business intelligence" (considered as the sum of the values of the codes)

2. Based on the "thinking styles" questionnaire, points are calculated that characterize the severity of each of the thinking styles. The authors of this questionnaire identified 5 styles of thinking:

- Synthetic style of thinking (manifests itself in creating something new, original, combining dissimilar, often opposite ideas, views, and performing thought experiments)

- Idealistic style of thinking (manifested in a tendency to intuitive, global assessments without performing a detailed analysis of problems).

- Pragmatic style of thinking (based on direct personal experience, using the materials and information that are easily available, trying to get a concrete result (albeit limited), practical gain as quickly as possible).

- Analytical style of thinking (focused on systematic and comprehensive consideration of a question or problem in those aspects that are set by objective criteria, inclined to logical, methodical, thorough (with an emphasis on details) manner of solving problems).

- Realistic style of thinking (focused only on the recognition of facts, and "real" is only what we can directly feel, personally see or hear, touch).

3. Based on the obtained numerical values, a matrix of correlations between variables is compiled and analyzed, and a conclusion is made.

\section{ANALYSIS}

The respondents were students and lecturers of Institute of Economics and management in Nizhny Novgorod state engineering and economic university.

Based on the study of their responses, the following correlation matrix was compiled (table 1).

TABLE I. TABLE OF CORRELATIONS BETWEEN THE EXPRESSION OF DIFFERENT THINKING STYLES AND OPINIONS ABOUT THE DEGREE AND NATURE OF BUSINESS INTELLIGENCE INFLUENCE ON VARIOUS PARAMETERS OF THE ORGANIZATION

\begin{tabular}{|c|c|c|c|c|c|c|}
\hline $\begin{array}{l}\text { Characteristic of an } \\
\text { organization that is affected } \\
\text { by business analytics }\end{array}$ & $\begin{array}{l}\text { Influence } \\
\text { parameter }\end{array}$ & $\begin{array}{c}\text { The expression of } \\
\text { a synthetic style } \\
\text { of thinking }\end{array}$ & $\begin{array}{c}\text { The expression of } \\
\text { idealistic style of } \\
\text { thinking }\end{array}$ & $\begin{array}{c}\text { The expression } \\
\text { of pragmatic } \\
\text { style of thinking }\end{array}$ & $\begin{array}{l}\text { The expression of } \\
\text { analytical style of } \\
\text { thinking }\end{array}$ & $\begin{array}{c}\text { The expression of } \\
\text { realistic style of } \\
\text { thinking }\end{array}$ \\
\hline & Degree & 0.492 & 0.302 & 0.461 & -0.254 & 0.269 \\
\hline & Character & 0.201 & -0.277 & 0.483 & 0.192 & -0.445 \\
\hline & Degree & -0.046 & 0.175 & -0.370 & 0.186 & 0.352 \\
\hline & Character & -0.155 & -0.373 & 0.123 & -0.020 & -0.452 \\
\hline & Degree & 0.234 & 0.257 & 0.293 & -0.064 & 0.223 \\
\hline & Character & 0.017 & -0.361 & 0.253 & 0.288 & -0.276 \\
\hline & Degree & 0.034 & 0.259 & 0.057 & 0.069 & 0.089 \\
\hline & Character & -0.385 & -0.408 & -0.106 & 0.077 & -0.365 \\
\hline
\end{tabular}


At significance level of 0.05 , all correlations with a correlation coefficient modulo greater than 0.31 are significant. This allows drawing the following conclusions:

- The more a person has a synthetic or pragmatic style of thinking, the higher he / she estimates the degree of influence of business Analytics on the organization's innovation;

- The more a person has a pragmatic style of thinking, the more he is inclined to believe that business Analytics directly affects the innovation of the organization;

- The more a person has an analytical style of thinking, the more he is inclined to believe that business Analytics inversely affects the innovation of the organization;

- The more a person has a pragmatic style of thinking, the lower he / she estimates the degree of influence of business Analytics on the dynamism of the organization;

- The more a person has a realistic style of thinking, the higher he / she estimates the degree of influence of business Analytics on the dynamism of the organization;

- The more a person has an idealistic or realistic style of thinking, the more he is inclined to believe that business Analytics inversely affects the dynamism of the organization;

- The more a person has an idealistic style of thinking, the more he is inclined to believe that business Analytics inversely affects the innovative ambition of the organization;

- The more a person has a synthetic, idealistic, or realistic style of thinking, the more they tend to believe that business Analytics is inversely proportional to the size of the organization.

\section{CONCLUSION}

This research tries to investigate the relationship between the thinking style of students and teachers of the University's faculty of Economics and their opinions on the impact of business Analytics on various characteristics of the organization. According to the authors, it should be considered established that there are such relationships, which opens up a significant field of research in this direction.

\section{References}

[1] A.N. Ayvazli, "Scientific research on the improvement of commercial banks and application of innovations", Proc. of the Voronezh State
Univer. of Engineer. Technol., vol 81, no. 2, pp. 280-284, 2019. Retrieved from: https://doi.org/10.20914/2310-1202-2019-2-280-284

[2] D.A. Shageev, T.A. Chuhonceva, "Universal rapid method of assessment and management decision-making of situational problems in the enterprise", Proc. of the Voronezh State Univer. of Engineer. Technol., vol. 81, no. 2, pp. 359-376, 2019 Retrieved from: https://doi.org/10.20914/2310-1202-2019-2-359-376

[3] R.D. GhalichKhani, M. Hakkak, "A Model for Measuring the Direct and Indirect Impact of Business Intelligence on Organizational Agility with Partial Mediatory role of Empowerment (Case Study: Tehran Construction Engineering Organization (TCEO) and ETKA Organization Industries.co)", Proc. - Soc. and Behavioral Sci., vol. 230, pp. 413-421, 2016.

[4] W. Nasri, "Conceptual model of strategic benefits of competitive intelligence process", Int. J. of Busin. and Commerce, vol. 1, no. 6, pp. 25-35, 2012.

[5] C. Loebbecke, A. Picot, "Reflections on societal and business model transformation arising from digitization and big data analytics: A research agenda", J. of Strategic Inform. Syst., vol. 24, no. 3, pp. 149-157, 2015.

[6] A. Lönnqvist, V. Puhakka, "The Measurement of Business Intelligence", EDPACS, vol. 40, no. 3, pp. 1-14, 2009.

[7] C. Villar, J. Alegre, J. Pla-Barber, "Exploring the role of knowledge management practices on exports: A dynamic capabilities view", Int. Busin. Rev., vol. 23, no. 1, pp. 38-44, 2014.

[8] G. Silahtaroğlu, N. Alayoglu, "Using or Not Using Business Intelligence and Big Data for Strategic Management: An Empirical Study Based on Interviews with Executives in Various Sectors", Proc. - Soc. and Behavioral Sci., vol. 235, pp. 208-215, 2016.

[9] N. Dedić, C. Stanier, "Measuring the success of changes to Business Intelligence solutions to improve Business Intelligence reporting”, J. of Manag. Anal. DOI: 10.1080/23270012.2017.1299048

[10] T. Lukman et al., "Business intelligence maturity: The economic transitional context within Slovenia", Inform. Syst. Manag., vol. 28, no. 3, pp. 211-222, 2011.

[11] H.C. Chen, R.H.L. Chiang, V.C. Storey, "Business intelligence and analytics: from big data to big impact", MIS Quart, vol. 36, no. 4, pp. 1165-1188, 2012.

[12] T.-P. Liang, Yu-H. Liu, "Research Landscape of Business Intelligence and Big Data analytics: A bibliometrics study", Expert Syst. With Applicat., vol. 111, pp. 2-10, 2018.

[13] N. Ain, G. Vaia, W.H. DeLone, M. Waheed, "Two decades of research on business intelligence system adoption, utilization and success A systematic literature review", Decision Support Syst., vol. 125, pp. 113-126, 2019.

[14] C. D'Arconte, "Business Intelligence applied in Small Size for Profit Companies", Proc. Computer Sci., vol. 131, pp. 45-57, 2018.

[15] M. Brichni, S. Dupuy-Chessa, L. Gzara, N. Mandran, C. Jeannet, "BI4BI: A continuous evaluation system for Business Intelligence systems”, Expert Syst. With Applicat., vol. 76, pp. 97-112, 2017.

[16] K. Božič, V. Dimovski, "Business intelligence and analytics use, innovation ambidexterity, and firm performance: A dynamic capabilities perspective", J. of Strategic Inform. Syst. Retrieved from: https://doi.org/10.1016/j.jsis.2019.101578

[17] J. Jaklič, T. Grublješič, A. Popovič, "The role of compatibility in predicting business intelligence and analytics use intentions", Int. J. of Inform. Manag., vol. 43, pp. 305-318, 2018.

[18] A.F. Harrison, R.M. Brainson, The art of thinking. New York: Berkley Books, 1984, $193 \mathrm{p}$ 